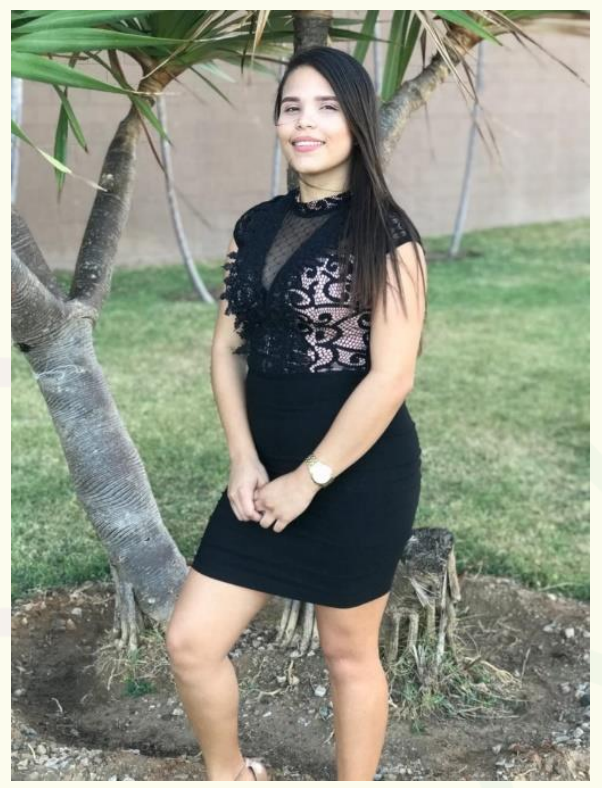

\title{
Uma trajetória de lutas e muitos sonhos sendo realizados
}

Meu nome é Maria Grasielly da Silva Nascimento, nasci em 19 de dezembro de 2001, sou filha de Sandra Maria Moura da Silva Nascimento e Josildo Sebastião do Nascimento, e a irmã mais velha de Maria Gabrielly da Silva Nascimento, os amores da minha vida. Poderíamos ser em torno seis, mas, infelizmente, minha mãe, em sua primeira gestação sofreu um aborto, e em sua última gestação o seu bebê veio a óbito em apenas seis meses de gravidez; mas tudo acontece na permissão de Deus. Moro com o meu companheiro Jaildo Pacheco da Silva, em Passira-PE, conhecida como a terra do bordado manual, onde passei minha infância repleta de alegria, nesta cidade.

Meus pais não concluíram os estudos, mas sempre me incentivaram, e ainda incentivam, sempre mostrando a importância dos estudos para as suas filhas, para que possamos ter um futuro melhor, pois eles não tiveram a oportunidade de terminar os estudos deles. Meu pai trabalhou desde cedo e não concluiu o Ensino Fundamental e minha mãe ajudava em casa e não concluiu o Ensino Médio. Hoje em dia meu pai tem a profissão de pedreiro e minha mãe é dona de casa, e sempre deram o melhor deles para nos educar. Sempre me dediquei aos estudos desde pequena, de ir à escola, ser uma boa aluna. Sempre fui aluna de rede pública, pois os meus pais não tinham condições de pagar uma escola particular para as suas duas filhas. 
Comecei a minha trajetória acadêmica com apenas três anos em uma escola do município de Passira, e terminei o meu Ensino Fundamental na mesma, e no $9^{\circ}$ ano, na disciplina de Ciências, tive o primeiro contato com a matéria de Química, o que despertou muito a minha atenção. Eu não tinha visto profundamente sobre a Química, era apenas o começo, mais já achei bastante interessante.

Com 14 anos entrei na escola estadual Cônego Fernando Passos, onde concluí o meu Ensino Médio, e também conheci muito sobre Química durante esses três anos. Minha professora do Ensino Médio, Sandra Soares, mesmo sendo formada em Biologia, mas com uma especialização na área da Química, explicava os conteúdos muito bem, e sempre durante as aulas, despertando minha atenção e interesse para a Química.

Desde o $2^{\circ}$ ano do Ensino Médio já queria ingressar no ensino superior para o curso de Licenciatura em Química, e sempre fui fascinada no jeito que os professores passam conhecimentos para os alunos, e no momento em que meus colegas tinham dúvidas em relação ao conteúdo de Química, eu repassava para eles o meu conhecimento e eles compreendiam, o que me deixava muito feliz por ter repassado o meu conhecimento para o próximo. Através da minha tia, fiquei sabendo que no IFPE, localizado em Vitória de Santo Antão, tinha o curso de Licenciatura em Química, e junto com colegas de turma realizamos nossos pedidos de isenção.

Logo após a inscrição para o Vestibular, no momento em que eu fiquei sabendo que passei no vestibular do IFPE, e principalmente no curso que eu desejava, foi um momento de muita felicidade para mim e para todos que acompanharam a minha trajetória de estudos e sabiam o quanto eu gostava de Química, os meus pais ficaram muito felizes e orgulhosos por ter uma filha que iria fazer faculdade e estava realizando um dos seus sonhos, e para mim isso era a realização de um sonho, que finalmente estava conseguindo concretizar.

Em 2018 estava começando o início da minha trajetória no IFPE, Campus Vitória de Santo Antão, e desde do primeiro dia de aula já sabia que tinha escolhido a carreira certa, e que ao decorrer desta trajetória encontraria muitas dificuldades, mas a minha vontade de seguir em frente foi muito maior do que as dificuldades que estavam surgindo.

No primeiro mês tive a oportunidade de ouvir falar sobre o PDVL, que é um programa voltado para a iniciação cientifica, e fiquei simplesmente fascinada por este 
programa, pois o seu principal o objetivo é desenvolver ações que auxiliem no despertar do interesse para os cursos de Licenciatura. Porém, no dia que eu soube sobre este programa, foi à noite e estava na faculdade, e era o último dia de inscrição, e infelizmente não iria ter como eu poder fazer a minha inscrição, pois chegava tarde em casa e estava sem internet. Depois de algumas semanas abriram as inscrições novamente, pois uma grande quantidades de alunos estavam na mesma situação que a minha, queriam participar do PDVL, mas não conseguiram se inscrever a tempo. Nesta segunda inscrição que abriram, consegui me inscrever, fiz a seleção e fui aprovada, sendo mais uma conquista na minha caminhada discente.

Inicialmente, me inseri no grupo de trabalhos de jogos, já que sempre fui fascinada por essa área, pois na escola que estudei meu Ensino Médio, alguns alunos que participavam do PDVL aplicavam jogos em relação aos conteúdos e eu percebia como isso me ajudava, e também ajudava os meu colegas a compreenderem melhor o conteúdo trabalhado na sala de aula, sem falar que a aula fica muito mais interessante.

Após ter me inserido no grupo de trabalhos de jogos, começaram as reuniões e ações nas escolas parceiras, tendo a oportunidade de voltar para a minha antiga escola, onde estudei o meu Ensino Médio. No primeiro dia que tive a oportunidade de fazer intervenção, foi um sentimento inexplicável, pois tive uma sensação diferente ao entrar na sala de aula, me senti diferente, de outra forma, pois eu estava lá para proporcionar saberes novos, onde um dia eu também aprendi. Depois de alguns meses, entrei, também, no grupo de trabalho de experimentos investigativos, onde era tudo novo para mim, pois no início da graduação senti muitas dificuldades em relação aos experimentos, já que nunca tinha presenciado um, e foi aí que percebi que esse GT iria me ajudar muito em relação a prática e suas abordagens.

O PDVL demonstrou, desde o início do curso, coisas maravilhosas, em que pude pela primeira vez ir em uma escola como docente em formação, pois é muito importante para nós como futuros professores saber o que vamos enfrentar depois que terminarmos o curso, e também aos métodos que podemos adotar para facilitar a aprendizagem dos nossos alunos, podendo observar as dificuldades encontradas pelos professores, principalmente, no início de sua formação. Está sendo um programa que me proporcionou o conhecimento cientifico, onde eu aprendi a fazer artigos científicos. No meu $2^{\circ}$ período consegui uma bolsa PIBIC - Programa de Iniciação Científica pelo 
CNPQ, e também sou membra do Grupo de Estudos e Pesquisas em Ensino de Ciências (GEPEC-IFPE), e assim aumentando ainda mais o meu desejo de continuar no curso e seguir em frente em minha carreira de docente.

Em meu $2^{\circ}$ período da graduação tive a oportunidade de participar de um congresso como o CONEDU e o COINTER, e também tive a oportunidade de participar como comissão organizadora do COINTER PDVL, que é um congresso internacional, que busca contribuir para o seu aprendizado e para sua vida acadêmica. Tive uma experiência incrível com bastante aprendizado; tive o meu trabalho premiado em primeiro lugar na modalidade de pôster. Naquele momento, fiquei sem acreditar e agradeço muito ao PDVL por ter me mostrado esse caminho científico, me ajudado na escrita, me ensinado os componentes para construir um bom artigo, e por me mostrar a importância de tudo isso em minha vida acadêmica.

Agora em 2020.2 fui aprovada no PIBID (Programa Institucional de Bolsa de Iniciação à Docência), voluntária do programa, e continuo participando do grupo de trabalho de jogos e de experimentos investigativos, onde estou me empenhando cada dia mais, e só tenho a agradecer às pessoas que compõe o grupo do PDV. Essas pessoas são muito especiais, dedicadas e buscam sempre ver o seu maior desempenho. Sou grata, também, à minha orientadora, pois através dela conheci o PDV, onde cresci como pessoa e profissionalmente, e por sempre acreditar em mim, no meu potencial, por me apoiarem no meu crescimento acadêmico. Só tenho a agradecer, pois o PDV foi um elemento essencial em minha vida, agradeço a todos, inclusive a Deus e às pessoas que fazem parte da minha trajetória, que acreditam em mim e que sempre me apoiaram desde o início, que foi a minha família, pois isso foi essencial para isso tudo acontecer.

Sei que meu percurso é extenso, tenho muito a batalhar para concluir o curso, ser uma ótima profissional e pôr em prática o que eu aprendi durante a minha formação no programa; mostrar a Química para os meus futuros alunos de forma diferente e dinâmica para que venha despertar neles a vontade de ingressar nesta profissão. Tenho muitos sonhos, inclusive em passar em mestrado, doutorado, concursos públicos, entre diversos outros sonhos, e sei que com fé e bastante dedicação, aos poucos vou alcançando cada um deles. 